\title{
The fear of needles: A systematic review and meta-analysis
}

\author{
Jennifer McLenon ${ }^{1}$ (D) | Mary A.M. Rogers ${ }^{2}$
}

${ }^{1}$ School of Public Health, University of Michigan, Ann Arbor, Michigan

${ }^{2}$ Department of Internal Medicine, University of Michigan, Ann Arbor, Michigan

\section{Correspondence}

Mary A.M. Rogers, Department of Internal Medicine, University of Michigan, Ann Arbor, MI.

Email: maryroge@umich.edu

\section{Funding information}

This research received no specific grant from any funding agency in the public, commercial, or not-for-profit sectors

\begin{abstract}
Aims: The aim of this study was to evaluate the prevalence of needle fear and summarize the characteristics of individuals who exhibit this fear.

Background: Injections are among the most common medical procedures, yet fear of needles can result in avoidance of preventive measures and treatment.

Design: Systematic review and meta-analysis.

Data Sources: MEDLINE (1966-2017), Embase (1947-2017), PsycINFO (19672017), and CINAHL (1961-2017) were searched, with no restrictions by age, gender, race, language, or country.

Review Methods: The prevalence of needle fear was calculated and restricted maximum likelihood random effects models were used for meta-analysis and meta-regression.

Results: The search yielded 119 original research articles which are included in this review, of which 35 contained sufficient information for meta-analysis. The majority of children exhibited needle fear, while prevalence estimates for needle fear ranged from $20-50 \%$ in adolescents and $20-30 \%$ in young adults. In general, needle fear decreased with increasing age. Both needle fear and needle phobia were more prevalent in females than males. Avoidance of influenza vaccination because of needle fear occurred in $16 \%$ of adult patients, $27 \%$ of hospital employees, $18 \%$ of workers at long-term care facilities, and $8 \%$ of healthcare workers at hospitals. Needle fear was common when undergoing venipuncture, blood donation, and in those with chronic conditions requiring injection.

Conclusions: Fear of needles is common in patients requiring preventive care and in those undergoing treatment. Greater attention should be directed to interventions which alleviate fear in high-risk groups.

KEYWORDS

anxiety, fear, injection, medical nursing, mental health, needle, phobia
\end{abstract}

\section{1 | INTRODUCTION}

Certain medical devices are so valuable in the practice of nursing and medicine that they are used worldwide. The hypodermic needle is one such device. It is employed for vascular, intradermal, subcutaneous, and intramuscular access and for biopsy and drug delivery across an extensive range of tissues (e.g., epidural, intraperitoneal).
While routinely used in clinical settings such as hospitals and medical offices, hypodermic needles are also frequently used in community settings for public health purposes and in home settings for patients with disabilities.

Across these settings, it is often the nurse who administers injections or who draws blood. Indeed, these procedures are among the skills taught in nursing schools throughout the world (Altman, Wcisel, 
\& Kerestzes, 2010). Beyond the expertise required for the administration of injections, however, are the psychosocial aspects of such delivery which are experienced by the patient. Because fear of needles is one such emotion observed in some patients who may anticipate pain, we conducted a systematic review of the fear of needles to explore the prevalence of this condition.

\section{1 | Background}

In a World Health Organization study of 10 major regions in the world, the mean frequency of needle injections ranges from 2-11 per person each year (Hutin \& Chen, 1999). Such injections are among the most common medical procedures, integral for both for preventive and treatment purposes. Yet, the fear of needles can delay or result in avoidance of preventive measures such as vaccination and may also deter blood donation, venipuncture during routine clinical evaluation and necessary treatment for various acute and chronic conditions (Wright, Yelland, Heathcote, Ng, \& Wright, 2009).

The terms "needle fear" and "needle phobia" both describe anxiety associated with needles and situations where needles or injections are used. However, needle phobia, as defined in the Diagnostic and Statistical Manual of Mental Disorders (DSM-IV), is a more extreme psychiatric disorder than generalized fear and often involves visual avoidance of the phobic stimulus and a diphasic vasovagal response featuring an initial increase and subsequent precipitous decrease in blood pressure, which can result in fainting (Jenkins, 2014). Needle phobia per se occurs less often than the generalized fear or anxiety associated with needles (Wright et al., 2009). Classical conditioning based on shared negative experiences of painful procedures may also invoke needle fear or phobia (Jenkins, 2014).

While fear may be acknowledged in practice, the extent of needle fear and the characteristics of persons affected have not yet been fully described. A better understanding of this condition may enable efforts to develop interventions to alleviate fear so that necessary procedures can be undertaken.

\section{2 | THE REVIEW}

\subsection{Aims}

This systematic review was conducted to: (a) assemble the body of literature available regarding the prevalence of needle fear and phobia; (b) summarize the prevalence of needle fear and phobia across demographic and clinical factors; and (c) assess the degree of vaccination avoidance because of needle fear.

\section{2 | Design}

A systematic review and meta-analysis were performed using established guidelines for observational research (Joanna Briggs Institute, 2015; Rogers, 2014; Stroup et al., 2000) and the general procedures outlined in the Preferred Reporting Items for Systematic Reviews and Meta-Analysis (PRISMA). The investigation was registered in

\section{Why is this research or review needed?}

- Patients often express a fear of needles or injection.

- Because the use of needles is ubiquitous in clinical settings, it is important to understand who is at higher risk of needle fear and the consequences of needle fear.

\section{What are the key findings?}

- Children exhibited the greatest fear of needles and the prevalence decreased with age.

- Women have greater needle fear than men, across all countries studied.

- Approximately one in six healthcare workers in long-term care facilities and 1 in 13 healthcare workers in hospitals avoided influenza vaccination because of the fear of needles.

\section{How should the findings be used to influence policy/practice/research/education?}

- Greater attention should be given to evidence-based approaches to alleviate fear during injections.

- Although some nonneedle options are available, there is a need to expand possible nonneedle alternatives for vaccination, fluid administration, and drug delivery.

PROSPERO, the International Prospective Register of Systematic Reviews (CRD42017070595).

\section{3 | Inclusion/exclusion criteria}

Eligibility criteria were: (a) scientific publication of original research; (b) fear or phobia of needles was investigated in the study; (c) data were included regarding the frequency of needle fear; and (d) the study was conducted in humans. We included articles that assessed fear of needles in general and the blood-injection-injury subtype of phobia as classified by the Diagnostic and Statistical Manual of Mental Disorders (DSM-IV).

\subsection{Search methods}

Data emanated from original research studies in which there were data regarding fear of needles. The bibliographic databases searched were Medical Literature Analysis and Retrieval System (MEDLINE, 1966-6/21/2017), Excerpta Medica dataBASE (Embase, 1947-6/21/ 2017), PsycINFO (1967-6/21/2017), and Cumulative Index to Nursing and Allied Health Literature (CINAHL, 1961-6/21/2017). There were no language restrictions nor were there restrictions by age, gender, race, or country of origin. The search terms included Boolean logic and controlled vocabularies to retrieve terms such as "injections" (MeSH Major Topic) and "needles" (MeSH Major Topic); 
the search strategy is listed in Appendix Table S1). We also conducted first-level backward chain searching of review articles on needle fear (i.e., evaluation of review articles for information regarding original studies).

\subsection{Search outcome}

Of the databases searched, there were 559 records retrieved and 357 records screened (Figure 1). Of the 227 full text articles assessed for eligibility, 119 satisfied eligibility criteria for this review. Study eligibility was ascertained independently by each author after review of the title and abstract. Differences in eligibility were flagged and resolved through discussion. This was followed by an independent review of eligibility by each author based on the entire research article. Reasons for exclusion were: (a) not an original research study ( $N=52)$, (b) prevalence of needle fear was not given ( $N=42$ ), and (c) the study did not examine needle fear $(N=14)$. Of the 119 studies included in this review, there were 35 articles that contained sufficient information to allow either meta-analysis of a summary measure or meta-regression.

\section{6 | Quality appraisal}

As the outcome of interest was prevalence, quality assessment was evaluated using epidemiologic standards established for accurate assessment of prevalence (Rothman, Greenland, \& Lash, 2012) and international standards for survey research (De Leeuw, Hox, \& Dillman, 2012). The criteria were: (a) the response rate; (b) the use of population-based representative sampling; (c) employing a random sample of the target reference group; and (d) whether a standardized instrument was used to assess needle fear or phobia. Each of the four elements was determined independently by the two authors; when there was disagreement after review, the original article was reviewed for clarity.

\section{7 | Data abstraction}

Data regarding study characteristics (e.g., first author, year of publication, location), study sample (e.g., age, gender, disease/condition), how fear/phobia was assessed, and prevalence of fear were independently extracted by each author. Differences were resolved through discussion.

\section{8 | Synthesis}

The prevalence and $95 \%$ exact confidence intervals were calculated for each study. Data were grouped according to the specific type of outcome measured (fear, phobia) and by personal characteristics (e.g., gender, occupation). Heterogeneity was evaluated by using $1^{2}$ (inconsistency index) and $\tau^{2}$ (between-study variance). For results that were heterogeneous (where a summary measure could not be pooled), data were plotted and meta-regression was performed. In meta-regression, between-study variance was modelled using random effects restricted maximum likelihood and $p$-values and confidence intervals were calculated using the Knapp-Hartung method. To pool prevalence, a restricted maximum likelihood random-effects model was used in meta-analysis and the Freeman-Tukey arcsin transformation was applied. Alpha was set at 0.05 (two-tailed) and results were conducted in Stata/MP 15.1 (College Station, TX).
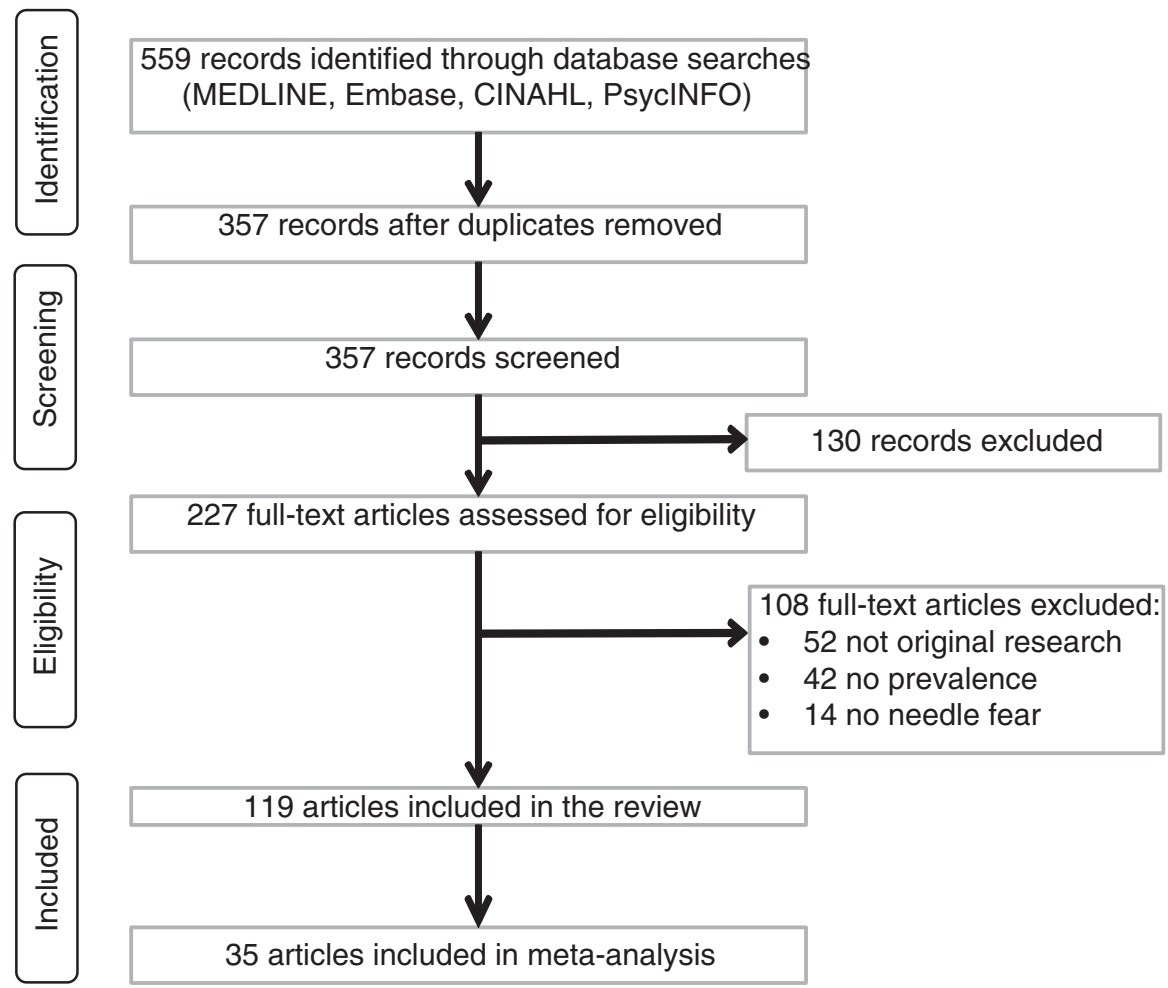

FIGURE 1 Flow diagram of eligible studies 


\section{RESULTS}

\section{1 | Overall characteristics of the studies}

The 119 eligible publications ranged from large population-based national surveys to small clinical studies (Appendix Table S2). The clinical studies generally included patients in whom injections were frequent such as children with type 1 diabetes and patients receiving routine dental procedures. There were also large population-based studies from several countries, including Australia, Germany, India, Mexico, the Netherlands, South Korea, Sweden, and the United States.

In quality assessment, 36 of the 119 eligible studies (30\%) had response rates $>80 \%$ (Appendix Table S3). Thirty studies involved a population-based sample and 22 extracted random samples from a targeted reference group. Of the 119 studies, 74.8\% involved the use of standardized instruments to assess fear or phobia.

\section{2 $\quad$ Prevalence by age}

There was considerable variation in the fear of needles by age $\left(I^{2}=99.9 \%, \tau^{2}=0.08\right)$. Fear of needles was greatest in children, especially younger children and decreased with age (Figure 2). The results of meta-regression indicated that, for every decade increase in age (years), there was an $8.7 \%$ (95\% Cl: $6.0 \%, 11.4 \%)$ decrease in the prevalence of needle fear $(p<0.001)$. The majority of children exhibited a fear of needles, while prevalence estimates ranged from $20-50 \%$ in adolescents. For adults who were $20-40$ years, the prevalence of needle fear approximated $20-30 \%$. It is noticeable that this prevalence dropped appreciably with older age and was $<5 \%$ at the oldest ages.

\section{3 | Prevalence by gender}

For both needle fear and needle phobia, the prevalence was greater in girls than boys and was greater in women than men. For studies that reported prevalence in both genders, the results were graphed by gender and the female:male prevalence ratio was calculated (Appendix Figure S1). In each of the studies, the point estimate

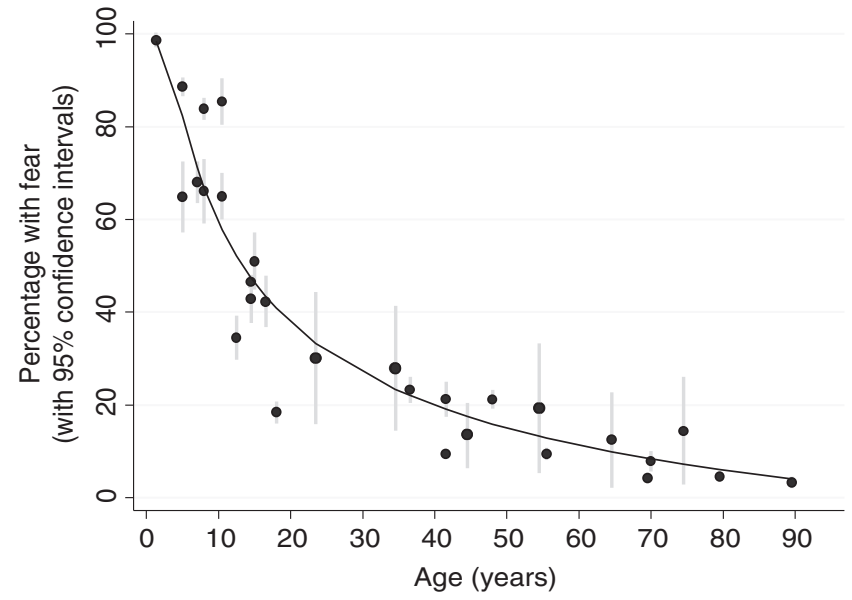

FIGURE 2 Fear of needles by age was greater in females than males. For needle fear, the pooled female:male prevalence ratio was $1.4(95 \% \mathrm{Cl}: 1.1,1.8)$ with $\mathrm{I}^{2}$ of $89.8 \%$ and $\tau^{2}$ of 0.067 . For needle phobia, the pooled female:male prevalence ratio was $1.7(95 \% \mathrm{Cl}: 1.3,2.1)$ with $\mathrm{I}^{2}$ of $63.4 \%$ and $\tau^{2}$ of 0.038 .

Gender differences in the prevalence of needle fear were evident across countries (Appendix Figure S1). Even with the gender differences, there was considerable heterogeneity in prevalence across countries. Needle fear was particularly high in Saudi Arabia and Israel, but quite low in Sweden. For needle phobia, Mexico and India had greater prevalence, while South Korea and Germany had low levels.

\subsection{Prevalence by disease/condition}

Many of the investigations reported fear of needles in patients with specific diseases or conditions. The results are shown in Table 1, with prevalence ranked within categories. Most of the studies were conducted in populations where injections were necessary for treatment. These included patients with cancer undergoing chemotherapy (prevalence of fear ranged from 15.7-84.0\%), individuals with diabetes (prevalence ranged from 1.3-41.7\%) and persons undergoing routine dental procedures (prevalence of fainting 1.7\%; prevalence of needle fear from 11.7-91.0\%). The prevalence of needle fear was also considerable for those with allergies, asthma, multiple sclerosis, spinal conditions, psychiatric disorders, and those undergoing dialysis. There was also high prevalence of needle fear when people were surveyed in various settings such as primary care clinics and in the hospital and in people who donate blood or who were planning to travel and required vaccination.

\subsection{Avoidance of medical procedures due to fear of needles}

The results showed evidence of vaccination avoidance for influenza because of the fear of needles or injections (Figure 3). The prevalence of avoidance due to fear was $27 \%$ in hospital employees, $18 \%$ in healthcare workers at long-term care facilities $\left(\mathrm{I}^{2}=0.0 \%\right.$, $\left.\tau^{2}<0.001\right), 8 \%$ in healthcare workers at hospitals $\left(I^{2}=23.8 \%\right.$, $\left.\tau^{2}=0.001\right), 16 \%$ in adult patients $\left(\mathrm{I}^{2}=0.0 \%, \tau^{2}<0.001\right)$, and $6 \%$ in older adult patients $\left(I^{2}=41.1 \%, \tau^{2}=0.002\right)$.

Results were similar for avoidance of other vaccines. In a nationally representative sample of US adults, $19 \%$ did not obtain a pneumococcal vaccination and $20 \%$ did not obtain a tetanus vaccination because of dislike of needles (Johnson, Nichol, \& Lipczynski, 2008). In a survey of 100 US physicians, $71 \%$ indicated that fear of needles was a contributing factor to not obtaining a tetanus vaccination; the figures were $71 \%$ and $69 \%$ for influenza vaccination and pneumococcal vaccination, respectively (Johnson et al., 2008). In a nationally representative survey of individuals 65 years and older in the US, $2.6 \%$ did not obtain a pneumococcal vaccination because the person "didn't like shots or needles" (Centers for Disease Control and Prevention (CDC), 1999). 
TABLE 1 Prevalence of needle fear or phobia by disease and clinical setting

\begin{tabular}{|c|c|c|c|c|c|c|}
\hline Category & $\begin{array}{l}\text { First } \\
\text { author }\end{array}$ & $\begin{array}{l}\text { Year of } \\
\text { publication }\end{array}$ & Prevalence & $\begin{array}{l}95 \% \\
\text { confide } \\
\text { interval }\end{array}$ & & Description of injection fear or phobia \\
\hline \multicolumn{7}{|c|}{ Conditions/Disease: } \\
\hline \multicolumn{7}{|l|}{ Allergy: } \\
\hline & Ferreira & 2013 & $11.0 \%$ & $6.8 \%$ & $15.2 \%$ & Fear of allergy shots \\
\hline \multicolumn{7}{|l|}{ Asthma: } \\
\hline \multicolumn{7}{|l|}{ Cancer: } \\
\hline & Kettwich & 2007 & $84.0 \%$ & $69.6 \%$ & $98.4 \%$ & Needle phobia of syringe. Children undergoing chemotherapy \\
\hline & Kettwich & 2007 & $68.0 \%$ & $49.7 \%$ & $86.3 \%$ & Needle phobia of butterfly needle. Children undergoing chemotherapy \\
\hline & Kettwich & 2007 & $64.0 \%$ & $45.2 \%$ & $82.8 \%$ & Needle phobia of syringe. Adults undergoing chemotherapy \\
\hline & Harris & 2009 & $16.9 \%$ & $10.8 \%$ & $24.7 \%$ & Patients with blood-injection-injury fear undergoing chemotherapy \\
\hline & Carey & 2005 & $15.7 \%$ & $10.7 \%$ & $20.8 \%$ & Fear of injections in patients undergoing intravenous chemotherapy \\
\hline \multicolumn{7}{|c|}{ Dental Patients: } \\
\hline & Naidu & 2010 & $91.0 \%$ & $85.4 \%$ & $96.6 \%$ & Anxious of local anaesthetic injection in gum \\
\hline & Taani & 2001 & $82.6 \%$ & $78.7 \%$ & $86.5 \%$ & Fear of feeling the needle injected \\
\hline & Taani & 2001 & $82.1 \%$ & $78.1 \%$ & $86.0 \%$ & Fear of seeing the injection needle \\
\hline & Earl & 1994 & $81.0 \%$ & $73.5 \%$ & $88.5 \%$ & Preoperative anxiety regarding injection before third molar surgery \\
\hline & Boyle & 2010 & $78.0 \%$ & $71.4 \%$ & $84.6 \%$ & Fear of seeing the anaesthetic needle \\
\hline & Elmore & 2014 & $25.5 \%$ & $16.7 \%$ & $34.3 \%$ & Afraid of needle injection in arm \\
\hline & VanWijk & 2012 & $25.5 \%$ & $19.9 \%$ & $31.1 \%$ & High preinjection anxiety \\
\hline & Milgrom & 1997 & $18.9 \%$ & $15.6 \%$ & $22.6 \%$ & Fear of the pain of injection during dental procedures \\
\hline & Vika & 2006 & $16.5 \%$ & $14.3 \%$ & $18.7 \%$ & High fear of dental injection, 18 years of age \\
\hline & Majstorovic & 2004 & $16.0 \%$ & $14.4 \%$ & $17.6 \%$ & Needle phobia in children \\
\hline & Kaakko & 1998 & $14.7 \%$ & $10.1 \%$ & $19.2 \%$ & Would not go ahead with dental injection due to anxiety/fear \\
\hline & Armfield & 2010 & $13.8 \%$ & $12.0 \%$ & $15.5 \%$ & Fear of dental needles or injections \\
\hline & Bajric & 2015 & $11.7 \%$ & $6.5 \%$ & $18.8 \%$ & Dental fear and anxiety in healthy youth, ages 8,12 , and 15 years \\
\hline & Vika & 2008 & $11.3 \%$ & $6.2 \%$ & $16.4 \%$ & Avoidance of dentist because of injection phobia, 18 years of age \\
\hline & Crawford & 2005 & $8.0 \%$ & $6.1 \%$ & $9.9 \%$ & Cancelled dental appointments because of apprehension regarding injections \\
\hline & Liddell & 1998 & $7.8 \%$ & $5.5 \%$ & $10.2 \%$ & Injection as unpleasant dental procedure \\
\hline & DeJongh & 1998 & $5.5 \%$ & $2.0 \%$ & $8.9 \%$ & Injection phobia \\
\hline & Milgrom & 1997 & $4.6 \%$ & $2.8 \%$ & $6.9 \%$ & Avoid dental appointments because of fear of injections \\
\hline & Vika & 2006 & $1.7 \%$ & $0.9 \%$ & $2.5 \%$ & Fainted with dental injection, 18 years of age \\
\hline \multicolumn{7}{|l|}{ Diabetes: } \\
\hline & Zambanini & 1999 & $41.7 \%$ & $32.7 \%$ & $50.8 \%$ & Troubled by more injections. Types $1 \& 2$ diabetes taking insulin \\
\hline & Howe & 2011 & $40.9 \%$ & $20.4 \%$ & $61.5 \%$ & Fear of injections. Type 1 diabetes in hospital at time of diagnosis \\
\hline
\end{tabular}


TABLE 1 (Continued)

\begin{tabular}{|c|c|c|c|c|c|c|}
\hline \multirow[t]{11}{*}{ Category } & \multirow{2}{*}{$\begin{array}{l}\text { First } \\
\text { author } \\
\text { Feitosa }\end{array}$} & \multirow{2}{*}{$\begin{array}{l}\text { Year of } \\
\text { publication } \\
2013\end{array}$} & \multirow{2}{*}{$\begin{array}{l}\text { Prevalence } \\
38.5 \%\end{array}$} & \multicolumn{2}{|c|}{$\begin{array}{l}95 \% \\
\text { confidence } \\
\text { interval }\end{array}$} & \multirow{2}{*}{$\begin{array}{l}\text { Description of injection fear or phobia } \\
\text { Fear of self-injection, pregnant women with diabetes at } 27 \text { weeks gestation }\end{array}$} \\
\hline & & & & $26.6 \%$ & $50.3 \%$ & \\
\hline & Hanas & 1997 & $34.2 \%$ & $26.8 \%$ & $41.6 \%$ & Phobia at the sight of a needle. Children and adolescents with type 1 diabetes \\
\hline & Cemeroglu & 2015 & $32.7 \%$ & $25.2 \%$ & $40.2 \%$ & $\begin{array}{l}\text { Caregivers of children and adolescents with type } 1 \text { diabetes. Fear of injections } \\
\text { or fear of infusion site changes for continuous subcutaneous insulin infusion }\end{array}$ \\
\hline & Zambanini & 1999 & $13.9 \%$ & $7.6 \%$ & $20.2 \%$ & $\begin{array}{l}\text { Avoid injections secondary to anxiety. Patients with types } 1 \& 2 \text { diabetes } \\
\text { taking insulin }\end{array}$ \\
\hline & Simmons & 2007 & $13.4 \%$ & $6.0 \%$ & $20.8 \%$ & Needle fear when I have to inject myself. Children with type 1 diabetes \\
\hline & Feitosa & 2013 & $12.7 \%$ & $4.5 \%$ & $20.9 \%$ & Fear of self-injection, pregnant women with diabetes at 37 weeks gestation \\
\hline & Howe & 2011 & $9.5 \%$ & $0.0 \%$ & $22.1 \%$ & Fear of injections. Type 1 diabetes at 6-9 months postdiagnosis \\
\hline & Hanas & 1997 & $8.2 \%$ & $3.9 \%$ & $12.5 \%$ & Pronounced needle phobia. Children and adolescents with type 1 diabetes \\
\hline & Simmons & 2007 & $1.4 \%$ & $0.0 \%$ & $4.3 \%$ & $\begin{array}{l}\text { Needle fear when my mom/dad tests my blood glucose. Children with type } 1 \\
\text { diabetes }\end{array}$ \\
\hline & Mollema & 2000 & $1.3 \%$ & $0.7 \%$ & $1.9 \%$ & Diabetes patients. Severe fear of self injection. Higher range in population \\
\hline \multicolumn{7}{|c|}{ Dialysis Patients: } \\
\hline & Mulder & 2013 & $55.3 \%$ & $44.7 \%$ & $65.9 \%$ & I try to avoid it when I have to inject myself \\
\hline & Mulder & 2013 & $41.2 \%$ & $30.7 \%$ & $51.7 \%$ & I try to avoid it at the moment that the nurse comes to insert the needle \\
\hline & Mulder & 2013 & $26.7 \%$ & $17.2 \%$ & $36.2 \%$ & I feel afraid when I have to inject myself \\
\hline \multicolumn{7}{|c|}{ Pregnancy/Prenatal counselling: } \\
\hline & Lilliecreutz & 2008 & $7.2 \%$ & $5.9 \%$ & $8.6 \%$ & Pregnant women with blood/injection phobia \\
\hline \multicolumn{7}{|c|}{ Psychiatric: } \\
\hline & Tompkins & 2007 & $57.8 \%$ & $42.2 \%$ & $72.3 \%$ & Needle fear in women who were drug users \\
\hline & Starcevic & 1997 & $27.1 \%$ & $16.4 \%$ & $40.3 \%$ & Blood injection injury phobia in patients with panic disorder with agoraphobia \\
\hline & Terra & 2007 & $2.9 \%$ & $0.0 \%$ & $6.2 \%$ & Blood-injection-injury phobia \\
\hline \multicolumn{7}{|c|}{ Spina bifida: } \\
\hline & Royle & 2008 & $19.0 \%$ & $7.3 \%$ & $30.7 \%$ & Injection anxiety \\
\hline \multicolumn{7}{|c|}{ Spinal cord injury: } \\
\hline & Royle & 2008 & $10.0 \%$ & $5.7 \%$ & $14.3 \%$ & Injection anxiety \\
\hline
\end{tabular}

Noncompliance with immunization due to needle fear occurred in $8 \%$ of children and $7 \%$ of parents in a sample from Canada; moreover, the degree of noncompliance was positively associated with the degree of fear (Taddio et al., 2012). For patients in Australia attending a general practice clinic, $64.1 \%$ of those with needle fear indicated avoiding future flu vaccination and $30.8 \%$ would avoid future tetanus vaccination; this compared with $19.5 \%$ and $7.0 \%$ for those without needle fear, respectively (Wright et al., 2009). In these patients, needle fear was also associated with avoiding blood tests, avoiding pain relief and avoiding blood donation (Wright et al.,
2009). In a study of Japanese children, $52.2 \%$ of those with needle fear were unwilling to receive a vaccine at baseline which decreased to $27.5 \%$ after a participatory educational event (Kajikawa, Maeno, \& Maeno, 2014).

Avoidance of other medical procedures was also demonstrated. Fear of needles was associated with avoiding having one's blood drawn (Deacon \& Abramowitz, 2006), avoiding insulin injections in patients with diabetes (Zambanini, Newson, Maisey, \& Feher, 1999), avoiding undergoing amniocentesis while pregnant (Peters, 1984) and cancelling a dental appointment or avoiding a dentist (Crawford, 
Author

Year

$\mathrm{N}$

Weight (\%)

Proportion $(95 \% \mathrm{Cl})$

Hospital employees (with \& without patient contact)

Watanakunakorn

1993

724

Health care workers at long-term care facilities

Heimberger $\quad 1995 \quad 757$

Subtotal $(R=0.0 \%$; Cochrane $Q, p=0.63)$

Health care workers at hospitals

$\begin{array}{lrrr}\text { Nichol } & 1997 & 152 & 15.14 \\ \text { Harbarth } & 1998 & 757 & 47.02 \\ \text { Begue } & 1998 & 43 & 4.88 \\ \text { Naz } & 2009 & 420 & 32.97\end{array}$

Subtotal $(R=23.8 \%$; Cochrane $Q, p=0.38)$

Pediatricians

Heininger

2003

25

Adult patients (any age)

Johnson

Wright

2008

2,002

2009

177

Subtotal $(R=0.0 \%$; Cochrane $Q, p=0.55)$

Older adult patients

$\begin{array}{llll}\text { Drociuk } & 1999 & 4,503 & 76.62\end{array}$

Zimmerman $2003 \quad 225$

Subtotal $(R=41.1 \%$; Cochrane $Q, p=0.19)$

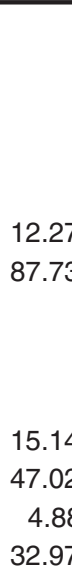

2.27

87.73

32.97

23.38

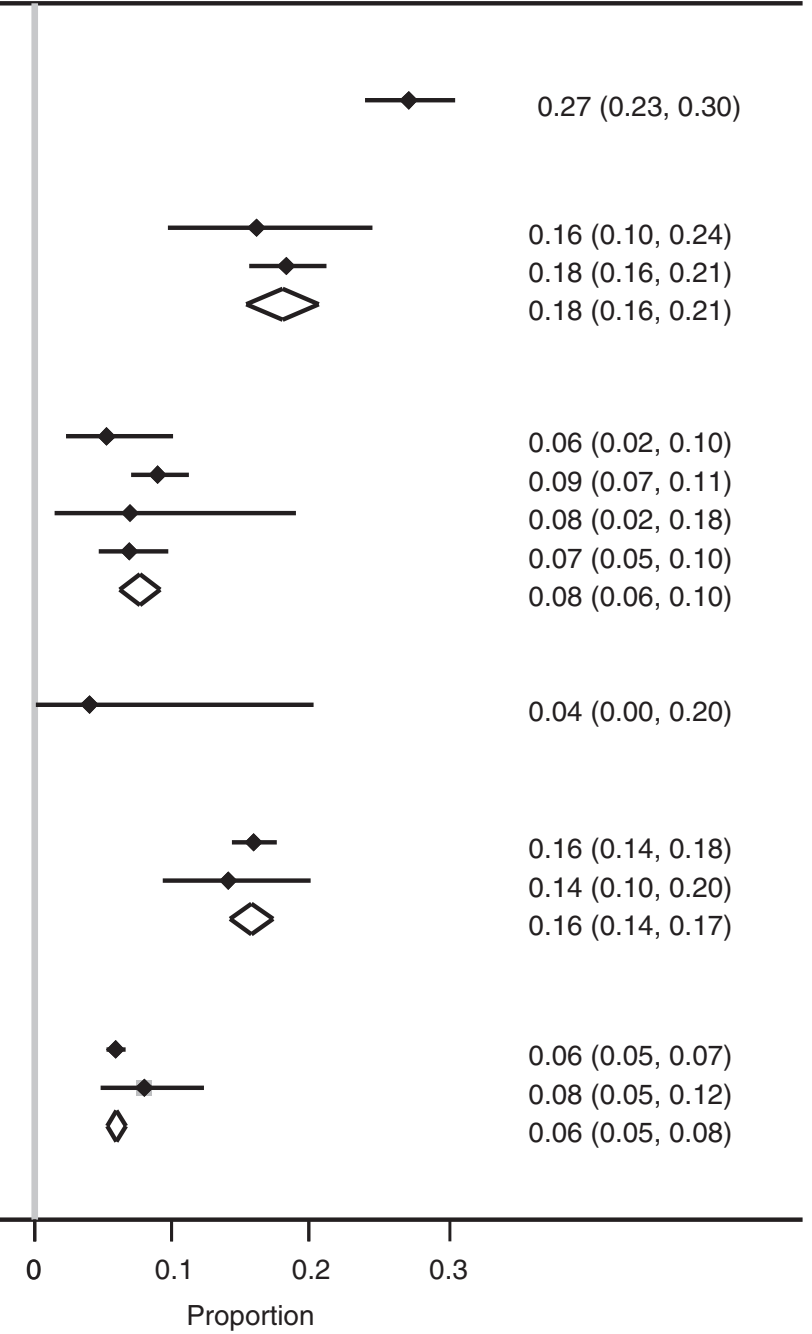

FIGURE 3 Forest plot of the proportion of individuals who avoided influenza vaccination because of needle fear

Niessen, Wong, \& Dowling, 2005; Hakeberg \& Berggren, 1997; Kaakko et al., 1998; Milgrom, Coldwell, Getz, Weinstein, \& Ramsay, 1997; Vika, Raadal, Skaret, \& Kvale, 2006).

\section{4 | DISCUSSION}

In this review, we found a significant variation in needle fear by age and gender. Young children and women exhibited higher prevalence of needle fear and phobia, regardless of country of origin. Throughout the world, women have largely taken the responsibility for their children's daily health concerns (World Bank, 2012). Even in developed countries, the vast majority of children's medical visits are handled by the mother (Daly \& Groes, 2017). As vaccinations and medical procedures often involve needles, the fear of such needles by a disproportionate number of children and mothers could be an underrecognized impediment to preventive measures and treatment. Fadel et al. (2017) found that, in the United States, younger infants and infants with younger mothers were more likely to have received no vaccinations. The odds of infants having no vaccinations were five times greater in those with younger mothers ( $<20$ years) compared to those with mothers $\geq 30$ years of age (Fadel et al., 2017).

The degree of needle fear in patients who require injections due to the nature of their disease was striking. For example, $40.9 \%$ of children with type 1 diabetes were fearful of injections when they were first diagnosed in the hospital, although this declined to $9.5 \%$ at the third clinic visit which was 6-9 months after the initial diagnosis (Howe, Ratcliffe, Tuttle, Dougherty, \& Lipman, 2011). Caregivers of patients with type 1 diabetes also reported fear of injections or fear of infusion site changes for continuous subcutaneous insulin infusion; this occurred in $32.7 \%$ of caregivers in one study (Cemeroglu et al., 2015). Moreover, they found that patients with type 1 diabetes who exhibited more fear had greater glycated haemoglobin levels. For some patients with long-standing type 1 diabetes, it may be difficult to discern whether the fear emanates from the injection itself or from anticipation of a hypoglycaemic event. Fear of selfinjection for pregnant women with gestational diabetes was also 
shown to be quite prevalent-38.5\% at 27 weeks gestation (Feitosa, Sampaio, Batista, \& Pinheiro, 2013).

Avoidance of preventive measures due to needle fear also occurred. We found that $8 \%$ of healthcare workers in hospitals and $18 \%$ of workers in long-term care facilities avoided influenza vaccination because of the fear of needles. There was also evidence of avoidance of vaccination for tetanus and pneumococcal disease (CDC, 1999; Johnson et al., 2008). Relatively small reductions in vaccine coverage have been shown to result in significant increases in disease cases with appreciable rises in public sector costs (Lo \& Hotez, 2017). Healthcare worker vaccination leads to less staff absenteeism due to illness (Van Buynder et al., 2015) and greater nurse staffing levels have been associated with lower patient mortality (Aiken et al., 2014).

\section{1 | Limitations}

This review is limited by the inherent characteristics of the underlying original research articles. For population statistics, not all samples were randomly chosen and, for clinical samples, some involved referrals while others included a small number of participants. Authors often used different scales or types of questions for assessing fear and, therefore, there is a need for studies to determine the accuracy and reliability of such patient-reported outcomes and to develop a more unified approach to assessment so that prevalence can be compared across settings and cultures. Moreover, relevant technologies continuously change so that review and evaluation of patient outcomes using these devices require constant updating.

\subsection{Implications for future research and practice}

While needle fear is occasionally mentioned as a contributor to vaccine hesitancy, there are relatively few studies designed to address this problem (Salmon, Dudley, Glanz, \& Omer, 2015). There is a lack of applied public health and clinical research on methods of delivery which target factors such as needle size, injection speed, or nonneedle approaches (Noel et al., 2015). It is perhaps not surprising that a routine childhood vaccine that does not involve a needle has the highest rates of vaccination (i.e., polio vaccination rate $=93.7 \%$ in year 2015 in the United States) (National Center for Health Statistics, 2017). Approaches meant to reduce vaccine hesitancy target communication strategies for notification, reminders, or incentives but may not directly address the needle itself (Jarrett, Wilson, O'Leary, Eckersberger, \& Larson, 2015). In a randomized trial, a needle-free jet injector was found to be noninferior to the usual needle delivery system for influenza vaccination (McAllister et al., 2014). Yet needle-free jet injectors are not in widespread use. Other examples of novel approaches to replace typical injection procedures include microneedles, mouth strips, nanopatches, mucosal administration, and edibles (Ravi, Sadhna, Nagpaal, \& Chawla, 2015; Saroja, Lakshmi, \& Bhaskaran, 2011). Such needle-free methods could also potentially reduce needle- stick injuries which pose safety concerns in healthcare settings (Tarigan, Cifuentes, Quinn, \& Kriebel, 2015).

There have been various approaches to confront the underlying fear. Because healthcare professionals sometimes underestimate patients' needle anxiety (Lidén, Olofsson, Landgren, \& Johansson, 2012), improved assessment of symptoms may be necessary. There are guidelines for reducing pain during needle injections which is a reasonable starting point (Taddio et al., 2015). McMurtry et al. (2015) found that some psychological interventions targeted to needle fear and various muscle tension techniques to avoid fainting may provide benefits, although the quality of the evidence was low. Lilliecreutz, Josefsson, and Sydsjö (2010) conducted a trial in pregnant women who exhibited blood and injection phobia. In their study, cognitive behavioural therapy significantly reduced phobia and depressive symptoms. There is evidence that specific cognitive-behavioural interventions, hypnosis, and distraction (with nurse coaching) during an injection may lower distress in children and adolescents (Uman, Chambers, McGrath, \& Kisely, 2008).

\section{5 | CONCLUSION}

In conclusion, fear of needles occurs frequently in populations throughout the world, with higher prevalence at younger ages and in women. Fear of needles is common in patients requiring preventive care and those undergoing treatment. Greater attention should be given to alleviate this fear with an ultimate goal of improving health. We recommend implementation studies of nonneedle approaches to standard needle injection, with direct application to public health and clinical settings. We also recommend randomized trials to assess specific cognitive and behavioural strategies to alleviate fear.

\section{CONFLICT OF INTEREST}

No conflict of interest has been declared by the authors.

\section{AUTHOR CONTRIBUTIONS}

All authors have agreed on the final version and meet at least one of the following criteria [recommended by the ICMJE (http://www.ic mje.org/recommendations/)]:

- substantial contributions to conception and design, acquisition of data, or analysis and interpretation of data;

- drafting the article or revising it critically for important intellectual content.

\section{ORCID}

Jennifer McLenon (iD http://orcid.org/0000-0003-0444-3290

Mary A.M. Rogers (D) http://orcid.org/0000-0001-5519-3223 


\section{REFERENCES}

Agras, S., Sylvester, D., \& Oliveau, D. (1969). The epidemiology of common fears and phobia. Comprehensive Psychiatry, 10(2), 151-156.

Aiken, L. H., Sloane, D. M., Bruyneel, L., Van den Heede, K., Griffiths, P., Busse, R., ... McHugh, M. D. (2014). Nurse staffing and education and hospital mortality in nine European countries: A retrospective observational study. The Lancet, 383(9931), 1824-1830.

Altman, G. B., Wcisel, M. A., \& Kerestzes, P. (Eds.) (2010). Fundamental \& advanced nursing skills, 3rd ed. (p. 2010). Clifton Park, NY: Delmar.

Armfield, J. M. (2010). The extent and nature of dental fear and phobia in Australia. Australian Dental Journal, 55(4), 368-377.

Bahrmann, A., Abel, A., Zeyfang, A., Petrak, F., Kubiak, T., Hummel, J., ... Bahrmann, P. (2014). Psychological insulin resistance in geriatric patients with diabetes mellitus. Patient Education and Counseling, 94(3), 417-422.

Bajric, E., Kobasglija, S., \& Juric, H. (2015). Patients' reactions to local anaesthetic application devices in paediatric dentistry. Coll Antropol, 39(3), 685-690.

Begue, R. E., \& Gee, S. Q. (1998). Improving influenza immunization among healthcare workers. Infection Control \& Hospital Epidemiology, 19(7), 518-520.

Benjet, C., Borges, G., Stein, D. J., Méndez, E., \& Medina-Mora, M. E. (2012). Epidemiology of fears and specific phobia in adolescence: Results from the Mexican adolescent mental health survey. Journal of Clinical Psychiatry, 73(2), 152-158.

Berge, K. G., Vika, M., Agdal, M. L., Lie, S. A., \& Skeie, M. S. (2017). Reliability, validity and cutoff score of the intra-oral injection fear scale. Int J Paediatr Dent, 27(2), 98-107.

Berggren, U. (1992). General and specific fears in referred and selfreferred adult patients with extreme dental anxiety. Behaviour Research and Therapy, 30(4), 395-401.

Bienvenu, O. J., \& Eaton, W. W. (1998). The epidemiology of blood-injection-injury phobia. Psychological Medicine, 28(5), 1129-1136.

Boyle, C. A., Newton, T., \& Milgrom, P. (2010). Development of a UK version of CARL: A computer program for conducting exposure therapy for the treatment of dental injection fear. SAAD Dig, 26, 8-11.

Burstein, M., Georgiades, K., He, J. P., Schmitz, A., Feig, E., Khazanov, G. K., Merikangas, K. (2012). Specific phobia among U.S. adolescents: Phenomenology and typology. Depress Anxiety, 29(12), 1072-1082.

Carey, C. L., \& Harris, L. M. (2005). The origins of blood-injection fear/ phobia in cancer patients undergoing intravenous chemotherapy. Behavior Change, 22(4), 212-219.

Cemeroglu, A., Can, A., Davis, A., Cemeroglu, O., Kleis, L., Daniel, M., ... Koehler, T. (2015). Fear of needles in children with type 1 diabetes mellitus on multiple daily injections and continuous subcutaneous insulin infusion. Endocrine Practice, 21(1), 46-53.

Centers for Disease Control and Prevention (CDC). (1999). Reasons reported by Medicare beneficiaries for not receiving influenza and pneumococcal vaccinations-United States, 1996. MMWR. Morbidity and Mortality Weekly Report, 48(39), 886.

Cohen, L. L., Francher, A., MacLaren, J. E., \& Lim, C. S. (2006). Correlates of pediatric behavior and distress during intramuscular injections for invasive dental procedures. The Journal of Clinical Pediatric Dentistry, 31(1), 44-47.

Costello, C. G. (1982). Fears and phobias in women: A community study. Journal of Abnormal Psychology, 91(4), 280.

Cox, A. C., \& Fallowfield, L. J. (2007). After going through chemotherapy I can't see another needle. Eur J Oncol Nurs, 11(1), 43-48.

Crawford, S., Niessen, L., Wong, S., \& Dowling, E. (2005). Quantification of patient fears regarding dental injections and patient perceptions of a local noninjectable anesthetic gel. Compendium of Continuing Education In Dentistry (Jamesburg, NJ: 1995), 26(2 Suppl 1), 11-14.
Daly, M., \& Groes, F. (2017). Who takes the child to the doctor? Mom, pretty much all of the time. Applied Economics Letters, 24 (17), 1267-1276.

Davis, L. A., Ku, B. S., Griffin, B., \& Fields, J. M. (2013). Prevalence of needle phobia in patients with difficult venous access. Academic Emergency Medicine, 20(5), S141.

De Jongh, A., Bongaarts, G., Vermeule, I., Visser, K., De Vos, P., \& Makkes, P. (1998). Blood-injury-injection phobia and dental phobia. Behavior Research and Therapy, 36(10), 971-982.

De Leeuw, E. D., Hox, J., \& Dillman, D. (2012). International handbook of survey methodology. London, UK: Routledge.

de Vos, G., Shankar, V., Nazari, R., Kooragayalu, S., Smith, M., Wiznia, A., Rosenstreich, D. (2012). Fear of repeated injections in children younger than 4 years receiving subcutaneous allergy immunotherapy. Annals of Allergy, Asthma \& Immunology, 109(6), 465-469.

Deacon, B., \& Abramowitz, J. (2006). Fear of needles and vasovagal reactions among phlebotomy patients. Journal of Anxiety Disorders, 20(7), 946-960.

Depla, M. F., Margreet, L., van Balkom, A. J., \& de Graaf, R. (2008). Specific fears and phobias in the general population: Results from the Netherlands Mental Health Survey and Incidence Study (NEMESIS). Social Psychiatry and Psychiatric Epidemiology, 43(3), 200-208.

Doebling, S., \& Rowe, M. M. (2000). Negative perceptions of dental stimuli and their effects on dental fear. Journal of Dental Hygiene: JDH, 74(2), 110-116.

Earl, P. (1994). Patients' anxieties with third molar surgery. British Journal of Oral and Maxillofacial Surgery, 32(5), 293-297.

Elmore, J. R., Priest, J. H., \& Laskin, D. M. (2014). Do patients fear undergoing general anesthesia for oral surgery? Anesthesia Progress, 61(2), 69-72.

Essau, C. A., Conradt, J., \& Petermann, F. (2000). Frequency, comorbidity and psychosocial impairment of specific phobia in adolescents. Journal of Clinical Child Psychology, 29(2), 221-231.

Fadel, C. W., Colson, E. R., Corwin, M. J., Rybin, D., Heeren, T. C., Wang, C., \& Moon, R. Y. (2017). Maternal Attitudes and other factors associated with infant vaccination status in the United States, 2011-2014. The Journal of Pediatrics, 185, 136-142.

Feitosa, A. C. R., Sampaio, L. N., Batista, A. G. L., \& Pinheiro, C. B. (2013). Frequency of fear of needles and impact of a multidisciplinary educational approach towards pregnant women with diabetes. Rev Bras Ginecol Obstet, 35(3), 111-116.

Ferreira, M. B., Viegas, L. P., Santos, A. S., \& Barbosa, M. P. (2013). Allergy shots: Do patients feel pain or fear? Allergol Immunopathol (Madr), 41(4), 273-275.

Fradet, C., McGrath, P. J., Kay, J., Adams, S., \& Luke, B. (1990). A prospective survey of reactions to blood tests by children and adolescents. Pain, 40(1), 53-60.

Goodenough, B., Thomas, W., Champion, G. D., Perrott, D., Taplin, J. E., von Baeyer, C. L., \& Ziegler, J. B. (1999). Unravelling age effects and sex differences in needle pain: Ratings of sensory intensity and unpleasantness of venipuncture pain by children and their parents. Pain, 80(1-2), 179-190.

Hakeberg, M., \& Berggren, U. (1997). Dimensions of the Dental Fear Survey among patients with dental phobia. Acta Odontologica Scandinavica, 55(5), 314-318.

Halliday, L., Thomson, J. A., Roberts, L., Bowen, S., \& Mead, C. (2003). Influenza vaccination of staff in aged care facilities in the ACT: How can we improve the uptake of influenza vaccine? Australian and New Zealand Journal of Public Health, 27(1), 70-75.

Hanas, R., \& Ludvigsson, J. (1997). Experience of pain from insulin injections and needle-phobia in young patients with IDDM. Practical Diabetes, 14(4), 95-99.

Harbarth, S., Siegrist, C. A., Schira, J. C., Wunderli, W., \& Pittet, D. (1998). Influenza immunization: Improving compliance of healthcare workers. Infection Control \& Hospital Epidemiology, 19(5), 337-342. 
Harris, L. M., Jones, M. K., \& Carey, C. L. (2009). Characteristics of Blood-Injection-Injury fears in people receiving intravenous chemotherapy. Current Psychology: A Journal for Diverse Perspectives on Diverse Psychological Issues, 28(2), 124-132.

Heimberger, T., Chang, H. G., Shaikh, M., Crotty, L., Morse, D., \& Birkhead, G. (1995). Knowledge and attitudes of healthcare workers about influenza: Why are they not getting vaccinated? Infection Control \& Hospital Epidemiology, 16(7), 412-415.

Heininger, U., Bächler, M., \& Schaad, U. B. (2003). Attitudes of pediatricians regarding influenza self-immunization: A survey in a Swiss university children's hospital. The Pediatric Infectious Disease Journal, 22(5), 391-394. https://doi.org/10.1097/01.inf.0000066901. 59298.a8

Howe, C. J., Ratcliffe, S. J., Tuttle, A., Dougherty, S., \& Lipman, T. H. (2011). Needle anxiety in children with type 1 diabetes and their mothers. MCN; American Journal of Maternal Child Nursing, 36(1), 25-31.

Hsieh, Y. C., Liu, H. T., \& Cho, Y. H. (2012). Reducing fear in preschool children receiving intravenous injections. J Nurs, 59(3), 79-86.

Humphrey, G. B., Boon, C. M., \& van de Wiel, H. B. (1992). The occurrence of high levels of acute behavioral distress in children and adolescents undergoing routine venipunctures. Pediatrics, 90(1), 87-91.

Hutin, Y. J., \& Chen, R. T. (1999). Injection safety: A global challenge. Bulletin of the World Health Organization, 77(10), 787.

Jacobsen, P. B. (1991). Treating a man with needle phobia who requires daily injections of medication. Hospital \& Community Psychiatry, 42(9), 877-878. https://doi.org/10.1176/ps.42.9.877

Jarrett, C., Wilson, R., O'Leary, M., Eckersberger, E., \& Larson, H. J. (2015). Strategies for addressing vaccine hesitancy-A systematic review. Vaccine, 33(34), 4180-4190.

Jenkins, K. (2014). II. Needle phobia: A psychological perspective. BJA: British Journal of Anaesthesia, 113(1), 4-6.

Joanna Briggs Institute. (2015). The Joanna Briggs institute method for systematic review research quick reference guide. Version 4.0. Adelaide: Queen's Joanna Briggs Collaboration.

Johnson, D. R., Nichol, K. L., \& Lipczynski, K. (2008). Barriers to adult immunization. The American Journal Of Medicine, 121(7), S28-S35.

Kaakko, T., Milgrom, P., Coldwell, S. E., Getz, T., Weinstein, P., \& Ramsay, D. S. (1998). Dental fear among university students: Implications for pharmacological research. Anesthesia Progress, 45(2), 62.

Kajikawa, N., Maeno, T., \& Maeno, T. (2014). Does a child's fear of needles decrease through a learning event with needles? Issues in Comprehensive Pediatric Nursing, 37(3), 183-194.

Kettwich, S. C., Sibbett, W. L., Kettwich, L. G., Palmer, C. J., Draeger, H. T., \& Bankhurst, A. D. (2006). Patients with needle phobia? Try stress-reducing medical devices. Journal of Family Practice, 55(8), 697-700.

Kettwich, S. C., Sibbitt, W. L. Jr, Brandt, J. R., Johnson, C. R., Wong, C. S., \& Bankhurst, A. D. (2007). Needle phobia and stress-reducing medical devices in pediatric and adult chemotherapy patients. Journal of Pediatric Oncology Nursing, 24(1), 20-28.

Kim, S. J., Kim, B. N., Cho, S. C., Kim, J. W., Shin, M. S., Yoo, H. J., Kim, H. W. (2010). The prevalence of specific phobia and associated comorbid features in children and adolescents. Journal of Anxiety Disorders, 24(6), 629-634.

Kleinknecht, R. A. (1987). Vasovagal syncope and blood/injury fear. Behaviour Research and Therapy, 25(3), 175-178.

Kleinknecht, R. A. (1994). Acquisition of blood, injury and needle fears and phobias. Behavior Research and Therapy, 32(8), 817-823.

Kleinknecht, R. A., Kleinknecht, E. E., \& Thorndike, R. M. (1997). The role of disgust and fear in blood and injection — related fainting symptoms: A structural equation model. Behavior Research and Therapy, 35(12), 1075-1087.

Kleinknecht, R. A., \& Lenz, J. (1989). Blood/injury fear, fainting and avoidance of medically-related situations: A family correspondence study. Behaviour Research and Therapy, 27(5), 537-547.
Kleinknecht, R. A., Thorndike, R. M., \& Walls, M. M. (1996). Factorial dimensions and correlates of blood, injury, injection and related medical fears: Cross validation of the medical fear survey. Behavior Research and Therapy, 34(4), 323-331.

Kose, S., \& Mandiracioglu, A. (2007). Fear of blood/injection in healthy and unhealthy adults admitted to a teaching hospital. International Journal of Clinical Practice, 61(3), 453-457.

Liddell, A., \& Gosse, V. (1998). Characteristics of early unpleasant dental experiences. Journal of Behavior Therapy and Experimental Psychiatry, 29(3), 227-237.

Lidén, Y., Olofsson, N., Landgren, O., \& Johansson, E. (2012). Pain and anxiety during bone marrow aspiration/biopsy: Comparison of ratings among patients versus health-care professionals. European Journal of Oncology Nursing, 16(3), 323-329.

Lilliecreutz, C., \& Josefsson, A. (2008). Prevalence of blood and injection phobia among pregnant women. Acta Obstetricia et Gynecologica Scandinavica, 87(12), 1276-1279.

Lilliecreutz, C., Josefsson, A., \& Sydsjö, G. (2010). An open trial with cognitive behavioral therapy for blood-and injection phobia in pregnant women-A group intervention program. Archives of Women's Mental Health, 13(3), 259-265.

Lo, N. C., \& Hotez, P. J. (2017). Public health and economic consequences of vaccine hesitancy for measles in the United States. JAMA Pediatrics, 171(9), 887-892.

Majstorovic, M., \& Veerkamp, J. S. (2004). Relationship between needle phobia and dental anxiety. J Dent Child (Chic), 71(3), 201-205.

McAllister, L., Anderson, J., Werth, K., Cho, I., Copeland, K., Bouveret, N. L., ... Cobb, D. K. (2014). Needle-free jet injection for administration of influenza vaccine: A randomised non-inferiority trial. The Lancet, 384(9944), 674-681.

McMurtry, C. M., Noel, M., Taddio, A., Antony, M. M., Asmundson, G. J., Riddell, R. P., ... Shah, V. (2015). Interventions for individuals with high levels of needle fear: Systematic review of randomized controlled trials and quasi-randomized controlled trials. The Clinical Journal of Pain, 31(Suppl 10), S109.

McWhorter, L. G., \& Gil-Rivas, V. (2014). The effect of brief functional relaxation on college students' needle anxiety during injected vaccinations. Journal of American College Health, 62(3), 166-172.

Merckelbach, H., Muris, P., de Jong, P. J., \& de Jongh, A. (1999). Disgust sensitivity, blood-injection-injury fear and dental anxiety. Clinical Psychology \& Psychotherapy, 6(4), 279-285.

Milgrom, P., Coldwell, S. E., Getz, T., Weinstein, P., \& Ramsay, D. S. (1997). Four dimensions of fear of dental injections. The Journal of the American Dental Association, 128(6), 756-762.

Miloyan, B., \& Eaton, W. W. (2016). Blood-injection-injury phobia in older adults. International Psychogeriatrics, 28(6), 897-902.

Mohr, D. C., Boudewyn, A. C., Likosky, W., Levine, E., \& Goodkin, D. E. (2001). Injectable medication for the treatment of multiple sclerosis: The influence of self-efficacy expectations and infection anxiety on adherence and ability to self-inject. Annals of Behavioral Medicine, 23(2), 125-132.

Mollema, E. D., Snoek, F. J., Pouwer, F., Heine, R. J., \& van der Ploeg, H. M. (2000). Diabetes Fear of Injecting and Self-Testing Questionnaire: A psychometric evaluation. Diabetes Care, 23(6), 765-769.

Mulder, M., Hoog, J. O., Buytene, S., \& De Vries, J. (2013). Validation of a screening instrument for the fear of injection in dialysis patients. J Ren Care, 39(4), 214-221.

Muris, P., Merckelbach, H., Schmidt, H., \& Tierney, S. (1999a). Disgust sensitivity, trait anxiety and anxiety disorders symptoms in normal children. Behavior Research and Therapy, 37(10), 953-961.

Muris, P., Schmidt, H., \& Merckelbach, H. (1999b). The structure of specific phobia symptoms among children and adolescents. Behavior Research and Therapy, 37(9), 863-868.

Naidu, R. S., \& Lalwah, S. (2010). Dental anxiety in a sample of West Indian adults. West Indian Medical Journal, 59(5), 567-572. 
National Center for Health Statistics. (2017). Health, United States, 2016: With chartbook on long-term trends in health. Hyattsville, MD: National Center for Health Statistics.

Naz, H., Cevik, F., \& Aykın, N. (2009). Influenza vaccination in healthcare workers. The Journal of Infection in Developing Countries, 3(01), 050-054. https://doi.org/10.3855/jidc.105

Neale, M. C., Walters, E. E., Eaves, L. J., Kessler, R. C., Heath, A. C., \& Kendler, K. S. (1994). Genetics of blood-injury fears and phobias: A population-based twin study. American Journal of Medical Genetics Part A, 54(4), 326-334.

Nichol, K. L., \& Hauge, M. (1997). Influenza vaccination of healthcare workers. Infection Control \& Hospital Epidemiology, 18(3), 189-194.

Nir, Y., Paz, A., Sabo, E., \& Potasman, I. (2003). Fear of injections in young adults: Prevalence and associations. American Journal of Tropical Medicine and Hygiene, 68(3), 341-344.

Noble, L. M., Farquharson, L., O'Dwyer, N. A., \& Behrens, R. H. (2014). The impact of injection anxiety on education of travelers about common travel risks. J Travel Med, 21(2), 86-91.

Noel, M., McMurtry, C. M., Chambers, C. T., \& McGrath, P. J. (2010). Children's memory for painful procedures: The relationship of pain intensity, anxiety and adult behaviors to subsequent recall. Journal of Pediatric Psychology, 35(6), 626-636. https://doi.org/10.1093/jpepsy/ jsp096

Noel, M., Taddio, A., McMurtry, C. M., Chambers, C. T., Riddell, R. P., \& Shah, V. (2015). HELPinKids\&Adults knowledge synthesis of the management of vaccination pain and high levels of needle fear: Limitations of the evidence and recommendations for future research. The Clinical Journal of Pain, 31(Suppl 10), S124.

Olatunji, B. O., Forsyth, J. P., \& Cherian, A. (2007). Evaluative differential conditioning of disgust: A sticky form of relational learning that is resistant to extinction. Journal of Anxiety Disorders, 21(6), 820-834.

Olatunji, B. O., Sawchuk, C. N., Moretz, M. W., David, B., Armstrong, T., \& Ciesielski, B. G. (2010). Factor structure and psychometric properties of the Injection Phobia Scale-Anxiety. Psychological Assessment, 22(1), 167-179.

Oosterink, F., De Jongh, A., \& Aartman, I. H. (2008). What are people afraid of during dental treatment? Anxiety-provoking capacity of 67 stimuli characteristic of the dental setting. European Journal of Oral Sciences, 116(1), 44-51.

Oosterink, F., De Jongh, A., \& Hoogstraten, J. (2009). Prevalence of dental fear and phobia relative to other fear and phobia subtypes. European Journal of Oral Sciences, 117(2), 135-143.

Oswalt, R. M., \& Hoff, T. E. (1975). The motivations of blood donors and nondonors: A community survey. Transfusion, 15(1), 68-72. https:// doi.org/10.1046/j.1537-2995.1975.15175103513.x

Park, S., Sohn, J. H., Hong, J. P., Chang, S. M., Lee, Y. M., Jeon, H. J., ... Cho, M. J. (2013). Prevalence, correlates and comorbidities of four DSM-IV specific phobia subtypes: Results from the Korean Epidemiological Catchment Area study. Psychiatry Research, 209(3), 596-603.

Patel, M. X., de Zoysa, N., Bernadt, M., \& David, A. S. (2008). A crosssectional study of patients' perspectives on adherence to antipsychotic medication: Depot versus oral. The Journal of Clinical Psychiatry, 69(10), 1548-1556.

Peretz, B., \& Efrat, J. (2000). Dental anxiety among young adolescent patients in Israel. International Journal of Paediatric Dentistry, 10(2), 126-132. https://doi.org/10.1046/j.1365-263x.2000.00181.x

Peretz, B., \& Mann, J. (2000). Dental anxiety among Israeli dental students: A 4-year longitudinal study. European Journal of Dental Education, 4(3), 133-137.

Peters, J. A. (1984). Amniocentesis and rhaphiphobia: A preliminary survey. Birth Defects Original Article Series, 20(6), 201-207.

Poulton, R., Thomson, W. M., Brown, R. H., \& Silva, P. A. (1998). Dental fear with and without blood-injection fear: Implications for dental health and clinical practice. Behavior Research and Therapy, 36(6), 591-597.
Ravi, A. D., Sadhna, D., Nagpaal, D., \& Chawla, L. (2015). Needle free injection technology: A complete insight. International Journal of Pharmaceutical Investigation, 5(4), 192.

Rogers, M. A. M. (2014). Comparative effectiveness research. New York, NY: Oxford University Press.

Rothman, K. J., Greenland, S., \& Lash, T. L. (2012). Modern epidemiology. Philadelphia, PA: Lippincott Williams \& Wilkins; Third edition.

Royle, J., \& Wright, L. (2008). Needle anxiety in the clinic: A needs assessment. British Journal of Nursing, 17(20), 1274-1279.

Salmon, D. A., Dudley, M. Z., Glanz, J. M., \& Omer, S. B. (2015). Vaccine hesitancy: Causes, consequences and a call to action. American Journal of Preventive Medicine, 49(6), S391-S398.

Sandín, B., Valiente, R. M., Chorot, P., Santed, M. A., \& Pineda, D. (2013). Dimensiones de sensibilidad al asco y predicción diferencial de los síntomas fóbicos $=$ Domains of disgust differentially predict types of phobic symptoms. Rev Psicopatol Psicol Clín, 18(1), 19-30.

Saroja, C. H., Lakshmi, P. K., \& Bhaskaran, S. (2011). Recent trends in vaccine delivery systems: A review. International Journal of Pharmaceutical Investigation, 1(2), 64.

Schienle, A., Schäfer, A., Stark, R., Walter, B., Kirsch, P., \& Vaitl, D. (2003). Disgust processing in phobia of blood-injection-injury. J Psychophysiol, 17(2), 87-93.

Shapiro, A. H. (1975). Behavior of kibbutz and urban children receiving an injection. Psychophysiology, 12(1), 79-82.

Sigström, R., Östling, S., Karlsson, B., Waern, M., Gustafson, D., \& Skoog, I. (2011). A population-based study on phobic fears and DSM-IV specific phobia in 70-year olds. Journal of Anxiety Disorders, 25(1), 148-153.

Simmons, J. H., McFann, K. K., Brown, A. C., Rewers, A., Follansbee, D., Temple-Trujillo, R. E., Klingensmith, G. J. (2007). Reliability of the Diabetes Fear of Injecting and Self-Testing Questionnaire in pediatric patients with type 1 diabetes. Diabetes Care, 30(4), 987-988.

Starcevic, V., \& Bogojevic, G. (1997). Comorbidity of panic disorder with agoraphobia and specific phobia: Relationship with the subtypes of specific phobia. Comprehensive Psychiatry, 38(6), 315-320.

Stinson, F. S., Dawson, D. A., Chou, S. P., Smith, S., Goldstein, R. B., Ruan, W. J., \& Grant, B. F. (2007). The epidemiology of DSM-IV specific phobia in the USA: Results from the National Epidemiologic Survey on Alcohol and Related Conditions. Psychological Medicine, 37(7), 1047-1059.

Stroup, D. F., Berlin, J. A., Morton, S. C., Olkin, I., Williamson, G. D., Rennie, D., ... Thacker, S. B. (2000). Meta-analysis of observational studies in epidemiology: A proposal for reporting. JAMA, 283(15), 2008-2012.

Taani, D. S. (2001). Dental fear among a young adult Saudian population. International Dental Journal, 51(2), 62-66.

Taani, D. Q. (2002). Dental attendance and anxiety among public and private school children in Jordan. International Dental Journal, 52(1), 25-29.

Taani, D. Q., El-Qaderi, S. S., \& Abu Alhaija, E. S. (2005). Dental anxiety in children and its relationship to dental caries and gingival condition. International Journal of Dental Hygiene, 3(2), 83-87.

Taddio, A., Ipp, M., Thivakaran, S., Jamal, A., Parikh, C., Smart, S., ... Katz, J. (2012). Survey of the prevalence of immunization non-compliance due to needle fears in children and adults. Vaccine, 30(32), 4807-4812.

Taddio, A., McMurtry, C. M., Shah, V., Riddell, R. P., Chambers, C. T., Noel, M., ... Lang, E. (2015). Reducing pain during vaccine injections: Clinical practice guideline. Canadian Medical Association Journal, 187(13), 975-982.

Tarigan, L. H., Cifuentes, M., Quinn, M., \& Kriebel, D. (2015). Prevention of needle-stick injuries in healthcare facilities: A meta-analysis. Infection Control \& Hospital Epidemiology, 36(7), 823-829.

Tellez, M., Kinner, D. G., Heimberg, R. G., Lim, S., \& Ismail, A. I. (2015). Prevalence and correlates of dental anxiety in patients seeking dental care. Community Dentistry and Oral Epidemiology, 43(2), 135-142. 
Terra, M. B., Garcez, J. P., \& Noll, B. (2007). Specific phobia: a transversal study with one hundred and three outpatients. Rev Psiquiatr Clin, 34(2), 68-73.

Thomas, D. R., Winsted, B., \& Koontz, C. (1993). Improving neglected influenza vaccination among healthcare workers in long-term care. Journal of the American Geriatrics Society, 41(9), 928-930.

Tolin, D. F., Lohr, J. M., Sawchuk, C. N., \& Lee, T. C. (1997). Disgust and disgust sensitivity in blood-injection-injury and spider phobia. Behavior Research and Therapy, 35(10), 949-953.

Tompkins, C. N., Ghoneim, S., Wright, N. M., Sheard, L., \& Jones, L. (2007). Needle fear among women injecting drug users: A qualitative study. Journal of Substance Use, 12(4), 281-291.

Turner, A. P., Williams, R. M., Sloan, A. P., \& Haselkorn, J. K. (2009). Injection anxiety remains a long-term barrier to medication adherence in multiple sclerosis. Rehabilitation Psychology, 54(1), 116.

Uman, L. S., Chambers, C. T., McGrath, P. J., \& Kisely, S. (2008). A systematic review of randomized controlled trials examining psychological interventions for needle-related procedural pain and distress in children and adolescents: An abbreviated Cochrane review. Journal of Pediatric Psychology, 33(8), 842-854.

Valentiner, D. P., Hood, J., \& Hawkins, A. (2005). Fainting history, disgust sensitivity and reactions to disgust-eliciting film stimuli. Pers Individ Dif, 38(6), 1329-1339.

Van Buynder, P. G., Konrad, S., Kersteins, F., Preston, E., Brown, P. D., Keen, D., \& Murray, N. J. (2015). Healthcare worker influenza immunization vaccinate or mask policy: Strategies for cost effective implementation and subsequent reductions in staff absenteeism due to illness. Vaccine, 33(13), 1625-1628.

van Dongen, A., Abraham, C., Ruiter, R. A., \& Veldhuizen, I. J. (2013). The influence of adverse reactions, subjective distress and anxiety on retention of first-time blood donors. Transfusion, 53(2), 337-343.

van Houtem, C. M., Aartman, I. H., Boomsma, D. I., Ligthart, L., Visscher, C. M., \& de Jongh, A. (2014). Is dental phobia a blood-injection-injury phobia? Depress Anxiety, 31(12), 1026-1034.

van Maanen, E. J., van Dinter, N., Versloot, J., \& Veerkamp, J. S. (2009). Fear of dental treatment among children. Influence of experience and psychological functioning. Ned Tijdschr Tandheelkd, 116(1), 3-8.

van Wijk, A., Lindeboom, J. A., de Jongh, A., Tuk, J. G., \& Hoogstraten, J. (2012). Pain related to mandibular block injections and its relationship with anxiety and previous experiences with dental anesthetics. Oral Surg Oral Med Oral Pathol Oral Radiol, 114(5 Suppl), S114-S119.

Veerkamp, J. S., \& Majstorovic, M. (2006). Dental anxiety and needle phobia in children. A relationship? Ned Tijdschr Tandheelkd, 113(6), 226-229.

Viar, M. A., Etzel, E. N., Ciesielski, B. G., \& Olatunji, B. O. (2010). Disgust, anxiety and vasovagal syncope sensations: A comparison of injectionfearful and nonfearful blood donors. Journal of Anxiety Disorders, 24(8), 941-945.

Viar-Paxton, M. A., Tomarken, A. J., Pemble, M. K., \& Olatunji, B. O. (2014). The role of domain-specific disgust propensity in behavioral avoidance and self-reported fainting symptoms in blood-injectioninjury phobia. J Exp Psychopathol, 5(2), 123-133. https://doi.org/ 10.5127/jep.030012
Vika, M., Raadal, M., Skaret, E., \& Kvale, G. (2006). Dental and medical injections: Prevalence of self-reported problems among 18-yr-old subjects in Norway. European Journal Of Oral Sciences, 114(2), 122-127.

Vika, M., Skaret, E., Raadal, M., Öst, L. G., \& Kvale, G. (2008). Fear of blood, injury and injections and its relationship to dental anxiety and probability of avoiding dental treatment among 18-year-olds in Norway. International Journal of Paediatric Dentistry, 18(3), 163-169.

Vossbeck-Elsebusch, A. N., \& Gerlach, A. L. (2012). The relation between disgust-sensitivity, blood-injection-injury fears and vasovagal symptoms in blood donors: Disgust sensitivity cannot explain fainting or blood donation-related symptoms. Journal of Behavior Therapy and Experimental Psychiatry, 43(1), 607-613.

Wagner, J., Malchoff, C., \& Abbott, G. (2005). Invasiveness as a barrier to self-monitoring of blood glucose in diabetes. Diabetes Technol Ther, 7(4), 612-619.

Wani, A. L., Ara, A., \& Bhat, S. A. (2014). Blood injury and injection phobia: The neglected one. Behavioural Neurology, 2014, 471340. https://doi.org/10.1155/2014/471340

Watanakunakorn, C., Ellis, G., \& Gemmel, D. (1993). Attitude of healthcare personnel regarding influenza immunization. Infection Control \& Hospital Epidemiology, 14(1), 17-20.

Wollin, S. R., Plummer, J. L., Owen, H., Hawkins, R. M., Materazzo, F., \& Morrison, V. (2004). Anxiety in children having elective surgery. Journal of Pediatric Nursing, 19(2), 128-132.

World Bank. (2012). World development report, p. 80

Wright, S., Yelland, M., Heathcote, K., Ng, S. K., \& Wright, G. (2009). Fear of needles: Nature and prevalence in general practice. Australian Family Physician, 38(3), 172.

Zambanini, A., \& Feher, M. D. (1997). Needle phobia in type 1 diabetes mellitus. Diabetic Medicine, 14(4), 321-323.

Zambanini, A., Newson, R. B., Maisey, M., \& Feher, M. D. (1999). Injection related anxiety in insulin-treated diabetes. Diabetes Research And Clinical Practice, 46(3), 239-246.

Zimmerman, R. K., Santibanez, T. A., Janosky, J. E., Fine, M. J., Raymund, M., Wilson, S. A., ... Nowalk, M. P. (2003). What affects influenza vaccination rates among older patients? An analysis from inner-city, suburban, rural and Veterans Affairs practices. The American Journal of Medicine, 114(1), 31-38.

\section{SUPPORTING INFORMATION}

Additional supporting information may be found online in the Supporting Information section at the end of the article.

How to cite this article: McLenon J, Rogers MAM. The fear of needles: A systematic review and meta-analysis. J Adv Nurs. 2019;75:30-42. https://doi.org/10.1111/jan.13818 
The Journal of Advanced Nursing (JAN) is an international, peer-reviewed, scientific journal. JAN contributes to the advancement of evidencebased nursing, midwifery and health care by disseminating high quality research and scholarship of contemporary relevance and with potential to advance knowledge for practice, education, management or policy. JAN publishes research reviews, original research reports and methodological and theoretical papers.

For further information, please visit JAN on the Wiley Online Library website: www.wileyonlinelibrary.com/journal/jan

\section{Reasons to publish your work in JAN:}

- High-impact forum: the world's most cited nursing journal, with an Impact Factor of 1.998 - ranked 12/114 in the 2016 ISI Journal Citation Reports @ (Nursing (Social Science)).

- Most read nursing journal in the world: over 3 million articles downloaded online per year and accessible in over 10,000 libraries worldwide (including over 3,500 in developing countries with free or low cost access).

- Fast and easy online submission: online submission at http://mc.manuscriptcentral.com/jan.

- Positive publishing experience: rapid double-blind peer review with constructive feedback.

- Rapid online publication in five weeks: average time from final manuscript arriving in production to online publication.

- Online Open: the option to pay to make your article freely and openly accessible to non-subscribers upon publication on Wiley Online Library, as well as the option to deposit the article in your own or your funding agency's preferred archive (e.g. PubMed). 